\title{
A New Ski Injury Registration System Architecture Using Mobile Applications to Enhance Skiing Safety
}

\author{
https://doi.org/10.3991/ijim.v10i4.5540 \\ Sule Yildirim-Yayilgan ${ }^{1}$, Yang Du ${ }^{1}$, Fisnik Dalipi ${ }^{1}$, Jonas C. Jeppesen ${ }^{2}$ \\ ${ }^{1}$ NTNU, Trondheim, Norway \\ ${ }^{2}$ Scandinavian Ski Safety Institute, Norway
}

\begin{abstract}
Mobile apps play an increasingly important role in healthcare institutions by enhancing the quality of healthcare services. Their role in sport injury prevention is also instrumental. In this article, we propose a system architecture for ski injury registration using mobile apps. Our work follows the idea of integrating and using mHealth apps to manage skiing injuries and to provide higher healthcare service quality and faster availability of data. With this work, we aim to greatly simplify the information workflow between the ski patrollers and the medical centers. Having the right information in the right place and on the right time for the injured person, the ski patroller then delivers to the medical centers that information in a format that is easy to analyze by the medical personnel and be prepared for possible interventions. To develop the mobile interfaces for the ski patrollers, nurses and doctors, we employ user-centered design. The overall system features and implementation are also explained and described in this paper.
\end{abstract}

For evaluation purposes of our proposed system architecture, we have conducted a traditional user test of the ski patroller system in collaboration with the ski patrollers in the ski resort of Trysil in Norway. Moreover, a heuristic evaluation with four evaluators is also conducted. The traditional test had two-evaluation points and based on the results of the tests, we obtained implications for enhancing the design of mobile interfaces for the proposed architecture.

Index Terms — skiing ingjuries, mobile apps, ski patroller.

\section{INTRODUCTION}

The recent advancements in the information and communication technologies significantly change the relation between the users and the computer systems. Nowadays, pervasive computing is becoming more and more the new reality, in which devices enhanced with intelligence and communication are all around us by changing the way we are interacting with our environment. eHealth solutions, are playing an important role in this new ecosystem dedicated for medical prevention, supervision and treatment [1][2]. Many countries and healthcare institutions are now relying on mobile applications for delivering high quality and safe healthcare services. These mobile health (mHealth) applications have great potential to transform healthcare by providing innovative solutions, approaches and interfaces [3], [4], [5].

Various sport disciplines are now using mHealth apps to prevent or manage injuries among athletes by helping to collect accurate and timely information from the scene of an incident. Many guidelines and tutorials are being currently developed with theories and principles of designing mobile apps for health [6], [7]. Skiing, as being one of the most famous among sport disciplines, particularly in Nordic countries, it is also related to a higher rate of injuries and is considered among high-risk sports. This is due to the variable and harsh weather and terrain conditions, various obstacles in the ski resort or mountains, such as other skiers, high speeds, trees, etc.

Inspired by the fact that the current technological innovations are poorly integrated, deployed and applied in managing ski injuries, and by following the idea for better management of ski injury data and reduced location dependency, we propose a system architecture for managing and registering skiing injuries, by giving some details and descriptions of our system presented in [8].

In this scenario, where skiing incidents are our first focus, the communication of the injury related information from the terrain (by ski patrollers) to the medical personnel is performed by using mobile device interfaces and wireless technology. We consider health services both at local community and at national levels. For this research, we have collaborated with ski patrollers from the Trysil ski resort in Norway. In order to realize their backgrounds, challenges and needs, we have conducted an interview with ski patrollers where we found that they spend approximately 80 percent of working hours in the mountain during the wintertime, while in 20 percent of the time they deal with completing injury report, resulting in extra burden and late submission. The information gathered by the ski patroller is not forwarded to the next level in the chain of treatment. Hence, the system loses important information in the process of handling the patient [8]. The traditional way of submitting and reporting of injured people does not always provide real time data on injury overview, on incidence location or severity. Therefore, we believe that our system, designed as a fast and an efficient registration system, will greatly simplify workflow between the ski patrollers and the medical centers, and help enhance healthcare services by improving the skier's chances of full recovery.

The rest of this paper is structured as follows: section 2 discusses related work in the field. The proposed system architecture and implementation are presented and explained in section 3 . In section 4 , we present the results of the traditional and heuristic evaluation. Finally, conclusions and future work are given in section 5 . 


\section{RELATED WORK}

In order to enhance skiing safety, researchers and sport specialists are continuously searching and developing ideas for new technological solutions. Such solutions also include the avalanche prediction systems Penetrometer and RECCO [9]. Moreover, many associations like International Ski Federation have been also researching, collecting data and developing different medical guides [10] to prevent injuries in the ski disciplines.

In the literature, there are several technologies and applications as regards to developing and integrating mobile solutions in the healthcare system [11], [12], [13], [14]. There are also works that address the interoperability between different medical systems by applying SOA and REST interface [15], [16], [17], [18], [19]. Another comprehensive study that addresses the challenges associated with consolidating ski hill injuries information collection, storage and handover procedures in the prehospital care chain is presented in [20]. The authors draw conclusions from two ethnographic case studies to explain issues related to interoperability of information management systems. In [21], a study of an exploratory research with experienced group of skiers to address group-sharing behavior among skiers is reported. Authors present several design ideas for mobile and wearable devices as well. Pfleging et. al [22] explain how the new technology development in pervasive computing have led to new services and products which enhance the skier's experiences.

Nonetheless, in the literature, the use of smartphone applications aiming at pervasive connectivity to provide a complete ski registration architecture including the interfaces is unaddressed by the research community.

To our knowledge, current research endeavors towards developing mobile apps for skiing injuries management are very rare. Recently, Jeppesen [23] raised the question of injuries risk in Norwegian ski resorts and discovered a need for better ways of managing the ski injury data while doing research on ski injuries at a local ski resort. The result of that research showed an under reporting of potential severe injuries by nearly $50 \%$, due to the limitations in a paper based system, which results in late submission, poor quality of data from the scene of the incident and sometimes inaccurate or loss of injury registration information.

\section{System ARCHITECTURE, USER INTERFACE DESIGN AND IMPLEMENTATION}

\section{A. Architecture Overview}

In our system, we employ the Resource Oriented Architecture (ROA). It has a simple structure and provides a uniform interface using Uniform Resource Identifier (URI). ROA is one of the most popular technologies for mobile applications due to its re-usability and flexibility features. ROA is cost-effective architecture. It helps save bandwidth by using JSON and provides an economical way of accessing data between client and server [24], which is especially useful for mobile apps and distributed systems. Until now, little work has been done in healthcare applications regarding skiing activities. For this reason, we built the ski registration system using the ROA pattern as our first attempt. The ultimate goal is to build energy-saving, secure and efficient applications for modern devices and to apply them to the next generation of mobile devices.

The ski registration system contains four modules:

1) Ski patroller app, the local medical center sever and the web service; 2) Doctor office app; 3) A synchronous module between hospital app and doctor office app; and 4) Data analysis app in the hospital.

The web service between ski patroller and doctor office has been implemented. The overall structure of ski injury registration system is given in Figure 1 and the basic messaging flow is shown in Figure 2.

The architecture is divided into three steps of operation. Firstly, the ski patrollers collect data, including text, audio and picture information from injured people. These records can be saved in iPhone and sent to remote server, either in offline mode or in real time, as long as the $4 \mathrm{G}$ network is connected. In addition to textual-based description, rescue teams can offer more detailed and precise re-
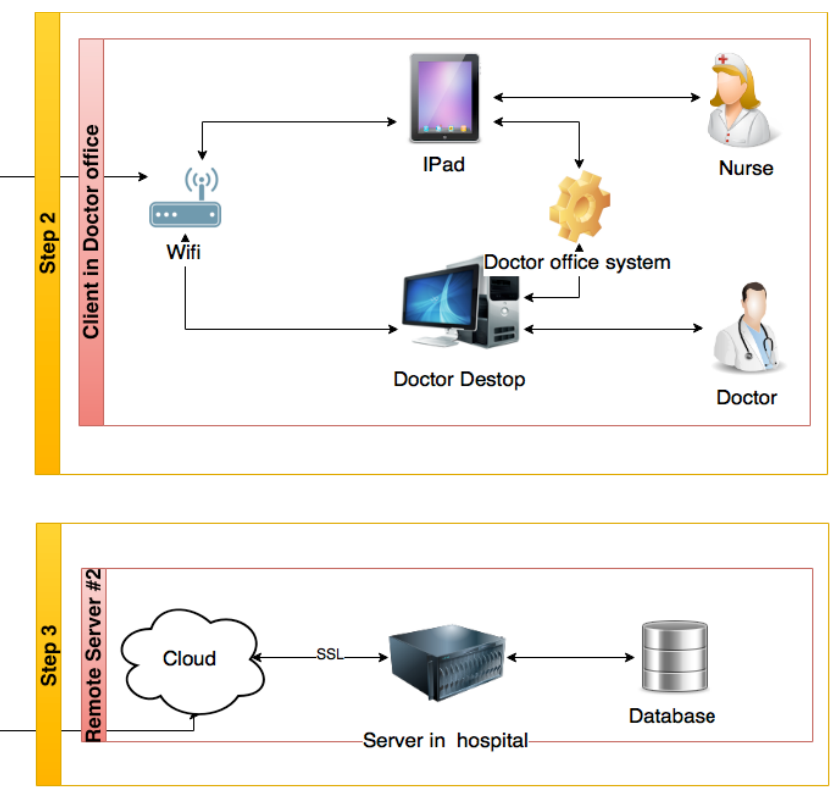

Figure 1. The overall structure of ski injury registration system 


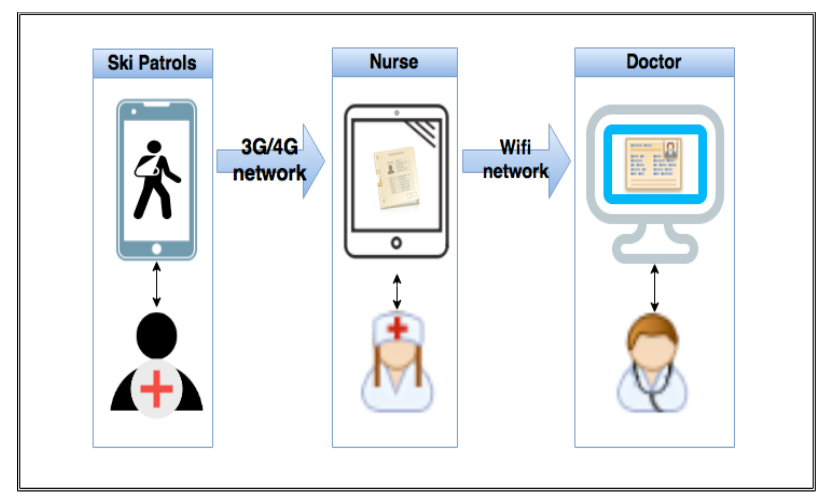

Figure 2. The flow of information in the system

ports to the doctors by using information from various media sources (audio, picture data). Once the report is sent to local medical center, in step 2, the nurse will access the data sent by the ski patroller and the nurse will schedule the injured person to a doctor according to his/her injured body part. Finally, the doctor will make a preliminary diagnosis based on the injured parts and their status through the report received in advance of the injured person's arrival at the local medical center. Further, the doctor may do analysis using the received data for the case as well as may visualize it on desktop or laptop. Further, using the data collected for all injuries up to date, the local medical center will be enabled to predict the incoming demand and the required manpower for handling the future cases. This way, the doctor office will improve the services and save labor cost in the long run.

In addition to these, there is a need of getting patient health record from hospital system to help doctor make diagnosis accurately and easily. In the final step, the registration system will integrate with hospital system using the cloud service.

The local medical center is able to get all patients' anamnesis, which helps doctor achieve high quality diagnosis.

\section{B. The Information flow}

We conducted a small user test over a period of 6 weeks in collaboration with two experienced ski patrollers. Based on the results of the test, we obtained implications for improving the design of mobile interfaces of the proposed architecture and the architecture in general (Figure 1).

Entering data to the ski registration system related to injured people, and providing feedback to the user (Nurse/doctor) in the clinical setting is done automatically in the proposed architecture. Furthermore, the data to transfer to the medical personnel further down in the chain of treatment must be stored and transmitted securely. The flow of information in the proposed system is as shown in Figure 2.

Little work in literature is done to help ski patrollers, who come in mountains across serious weather conditions, deal with fast registration digitally. In our case, the user interface (UI) of the mobile application for ski patroller is designed to make the registration fast and easy. It is designed to support the workflow at the injury site, giving the ski patroller a tool for registration while dealing with the injured person. The user interface for the doctor office desktop/laptop has the options to edit everything about the
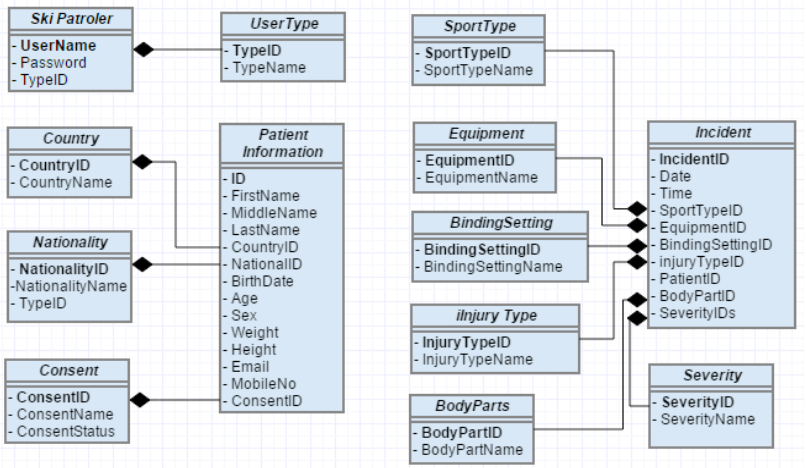

Figure 3. Database for ski injury registration system

injured person and the injury. Meanwhile, the user interface for the nurse iPad has the options to add more details regarding observations on injury parts and nurse treatment performed. We follow a UCD (User-Centered Design) process model while designing an interface specifically for ski patrollers.

The communication between mobile user and server involves a lot of data transmission. It directly affects the response time and may increase other potential overhead, resulting in unnecessary data transmission. For this reason, we implement our web service using RESTful interface, which can decrease transmission cost significantly. The web service plays an important role in our system. On one hand, it deals with the request from doctors, nurses, and the ski patroller. One the other hand, it informs the nurse to check the new message automatically when a new event (e.g. a message sent to the nurse) is updated. The nurse can distribute the message to the waiting list in doctor's office to help doctor make a final diagnosis for injured person. The diagnosis result will be finally saved in the database using the web service. The communication between the mobile user and the server is built over Secure Sockets Layer (SSL) using Https to keep a secure connection.

The overall ski injury registration system is functional in two parts: data collection and data analysis. Data collection includes the application that help collect data about the injured people. We use the database formatting shown in Figure 3, designed according to the requirement analysis provided by the staff in the local doctor office in Trysil. The database composes of 13 tables i.e., country, patient information and 35 variables e.g. countryID, CountryName for specifying the formatting of the data to be entered using the ski patroller app.

The data obtained about injured person is as follows:

a) User information about username and password, which is used for logging on the system

b) Personal information about injured people (name, gender, age, birth date, country, mobile and consent).

c) Information about incident, including injured part and its severity such as fracture, wound and sprain.

We have tested the database using test data and it is ready for testing with live data. For data analysis part, we have already obtained few statistics in the form of predictions $[25,26]$. These predictions are made using the artificial neural network methodology. The number of injured people on a daily basis, including the factors of temperature, precipitation, depth of snow, number of people skiing in the area, is predicted. 


\section{Interface design}

In our pilot study, our system is mainly designed for ski patroller in the first step. The user interface of the mobile application for ski patroller is designed to make the registration fast and easy. It requires minimal interaction, but also delivers sufficient data to the web-service. Ski patrollers may have to use it in hostile and cold environments. Therefore, the UI also supports interaction with gloves. The user interface for the doctor office desktop/laptop have the options to edit everything about the injured person and injury type. The user interface for the nurse iPad have the options to add more details about the injured person to make the treatment faster and easier for the doctor.

In Table 1, we show the followed system development lifecycle.

UCD defines a group of principles and methods to improve product usability and its user experience. User as core concept is involved in the UCD process [28]. The framework of UCD includes four basic modules: analysis, design, evaluation and implementation. However, in practice, we further extend it into six steps that is particularly useful in our work.

According to the special context and tasks in consideration, we outline the following main requirements: 1) the application should enable the patrol to register the injury with the personal information of the injured people. 2) It should provide the function of input, reserve and transform the details of the injury, for instance, the accurate location of injured part, the type of injury, such as fracture, wound, sprain or any other type, and the severity of injury. All of these information should take as little interaction steps and user's cognition as possible, making it possible for patrols to quickly input necessary information in case of emergency. 3) The application interface should be clear and distinguishable in the context of intense light outdoors.

4) All the operations on the application could be completed both with fingers and when wearing gloves. For that reason, the interface of the iPhone application should be convenient for use with gloves.

In the context of the specifications of the mobile ski patroller app interface, we make some special considerations to adequately address the needs of the users.

1. Considering the low temperature in the wild where the ski patrollers work, the UI should support interaction with gloves. This means that buttons and pictures are larger than normal since the field of touch is increased when using gloves.

2. To make the interface easier to identify under the intense light outdoors, we use a dark color for the foreground: the human body figure and white for the background to make them distinguishable. Therefore, the user can identify the human body figure on the screen and quickly find which part is injured.

3. Since many different people will use the application, there is a need for simplicity and fast learning curve; hence, the application should be self-explanatory. To achieve this we have used different colors to define severity levels $($ red $=$ severe, orange $=$ less severe, etc.) and illustrations of body parts.
TABLE I.

DESCRIPTION OF THE SYSTEM DEVELOPMENT LIFECYCLE

\begin{tabular}{|c|l|l|}
\hline 1 & $\begin{array}{l}\text { Assumption } \\
\text { and Planning }\end{array}$ & $\begin{array}{l}\text { Assumptions is created based on the users require- } \\
\text { ments at the beginning of life cycle. The planning } \\
\text { of each of cycle is decided at this stage. }\end{array}$ \\
\hline 2 & Analysis & $\begin{array}{l}\text { Analysis section includes: user analysis, require- } \\
\text { ment analysis, workflow analysis. An interview is } \\
\text { conduced to discover needs from ski patrollers and } \\
\text { we complete workflow analysis using scenarios in } \\
\text { the ski context. }\end{array}$ \\
\hline 3 & $\begin{array}{l}\text { Prototype } \\
\text { design }\end{array}$ & $\begin{array}{l}\text { We use conceptual model and metaphors to build } \\
\text { our prototype [27]. Different from traditional way } \\
\text { (using mockups), we implement our interface in } \\
\text { iPhone directly. This way, the user can offer feed- } \\
\text { back that is more accurate. }\end{array}$ \\
\hline 4 & $\begin{array}{l}\text { Prototype } \\
\text { evaluation }\end{array}$ & $\begin{array}{l}\text { The system is evaluated in a Norwegian ski resort } \\
\text { by two ski patrollers for a certain period. }\end{array}$ \\
\hline 5 & $\begin{array}{l}\text { Interface } \\
\text { improvement }\end{array}$ & $\begin{array}{l}\text { The user interface is considered to be improved } \\
\text { according to the feedback and recommendation } \\
\text { from the ski patrollers. }\end{array}$ \\
\hline 6 & $\begin{array}{l}\text { In the final step, we deployed our UI in to real app } \\
\text { and enabled to the user to test in a reality. }\end{array}$ \\
\hline
\end{tabular}

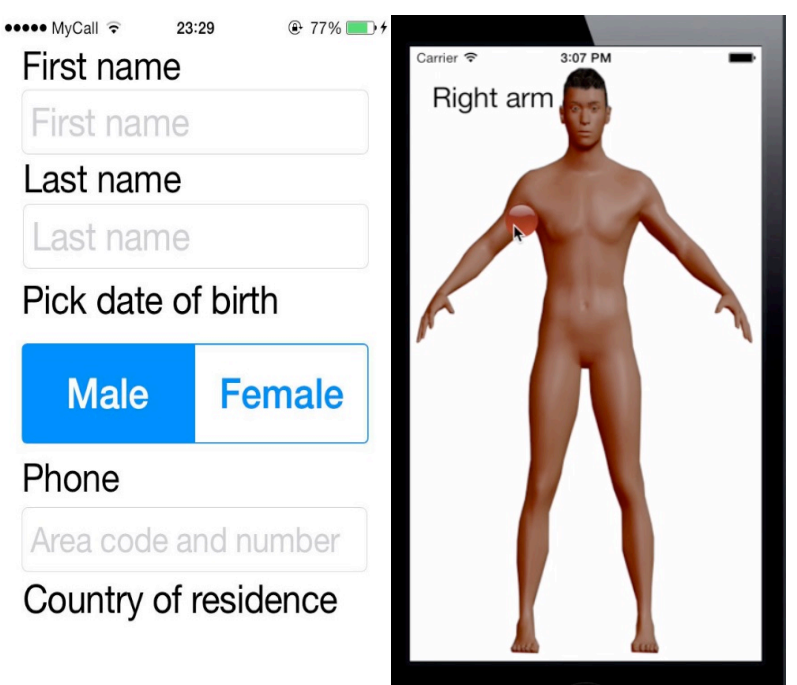

Figure 4. Several screen shorts from the user interface in the ski patroller app

4. To increase the accuracy of injury report, we design through two ways: First, we use a dynamic display of human body figure, which will automatically move the focus to the specific area when user touches it and then zooms in to the specific part in the next display with a more detailed figure of this area. Secondly, when the pointer comes to a certain part of the body image, the name of this body part will appear on the screen to prompt the user in case of errors. In this way, user can locate the injured area on the figure systematically, accurately and naturally.

5. To minimize user's cognition load and time consumption, we provide users with several options of the type and severity of injury by a drop down list rather than free input text-box. This may limit the diversity of input information, but facilitates rapid and accurate decision making, which is the first priority in our context. 


\section{PERFORMANCE EVALUATION}

In order to evaluate the proposed design of this prototype, after the initial development phase and programming, a traditional user testing and a heuristic evaluation has been conducted.

\section{A. Study 1: Traditional User Testing}

For traditional user testing, two professional skipatrolling participants used our prototype in Trysil, which is one of the largest ski resort in Norway. One of the skipatrolling participant was equipped with an iPhone 6 and the other with an iPhone $6+$. The results of this test are presented in Table II. The instructions included information regarding how to start recording, the informed consent part, ability to change date and position if needed, the change between different winter sport activities and how the need of information recorded changes accordingly. They received an instruction regarding the information recorded when registering the actual type of injury. Finally, the received information regarding how they continuously would have an overview of the ones they have treated during the day. The study period started 22nd of December 2014 and ended 31st of January 2015. It was divided into 2 phases. First, an introduction phase, where the ski patrollers could get used to handling the iPhone and the UI in real situations. After 2 weeks, we held the first evaluation meeting where we received feedback on the specifications of the mobile ski patroller app interface The feedback was taken back to the developing team, who prioritized and changed the user interface according to the feedback. The second edition of the pilot was uploaded and tested for 3 weeks..

Final evaluation meeting was held. From both ski patrollers we received the following comments: the usage of this mobile digital tool is reducing our workload regarding documentation. It supports the workflow and saves time due to the elimination of the transformation of written notes into paper scenes, which again is tapped into a program on a computer. They find this tool in their everyday work helping injured skiers and snowboarders. In more detail, the ski patroller 1 evaluates iPhone 6 as having a convenient size for fitting into pockets and is easily handled with gloves. Screen size of the phone is evaluated suitable for making touch selections. On the other hand, iPhone $6+$ is evaluated to be too large for storing it easily in a pocket and it is less optimal handling with a glove. However, the screen size of it gives a good workspace regarding touch. Ski patroller 2 evaluates iPhone 6 as having the best size of the two options for that reason it is preferable for use. Screen size of it is convenient for easy use and does not provide any restrictions.

Related to the color/light/darkness aspect of the phone displays, ski patroller 1 evaluates blue color in the text in upper part of the app difficult to read. However, figures and other text is easy to read and see (Figure and other text works fine.). The ski patroller 2 also reports that reading the top text is problematic; however, the rest of the display is easily readable.

The usability of the app in hostile environments is the next point to be evaluated by the ski patrollers. Ski patroller 1 report that the app works fine under snow conditions even with temperatures down to $-20{ }^{\circ} \mathrm{C}$. The conclusion of him is that the app work in snowy conditions. The ski pa-
TABLE II.

CASE STUDY RESULTS IN TRADITIONAL TESTING

\begin{tabular}{|c|c|c|}
\hline Themes & Ski patroller 1 & Ski patroller 2 \\
\hline Mobile unit & $\begin{array}{l}\text { iPhone 6: size fits into } \\
\text { pockets and is easily } \\
\text { handled with gloves. } \\
\text { Screen size: ok regarding } \\
\text { touch. } \\
\text { iPhone 6+: too large } \\
\text { regarding easy storing in } \\
\text { a pocket and less optimal } \\
\text { handling with a glove. } \\
\text { Screen size gives a good } \\
\text { workspace regarding } \\
\text { touch }\end{array}$ & $\begin{array}{l}\text { iPhone 6: best size of the } \\
\text { two. Preferable due to size. } \\
\text { Screen size: easy to use, no } \\
\text { restrictions } \\
\text { iPhone 6+: }\end{array}$ \\
\hline $\begin{array}{l}\text { Col- } \\
\text { or/light/darkne } \\
\text { ss }\end{array}$ & $\begin{array}{l}\text { Problems reading the text } \\
\text { in the upper part of app. } \\
\text { Figure and other text } \\
\text { works fine. }\end{array}$ & $\begin{array}{l}\text { Problems reading the top } \\
\text { text, otherwise it works fine } \\
\text { regarding readability. }\end{array}$ \\
\hline $\begin{array}{l}\text { Usability in } \\
\text { hostile envi- } \\
\text { ron- } \\
\text { ment }\end{array}$ & $\begin{array}{l}\text { Temperature: } \\
\text { Works fine, tested down } \\
\text { to }-20 \text { Celsius. } \\
\text { Snowy conditions: works } \\
\text { under snowy conditions }\end{array}$ & $\begin{array}{l}\text { Temperature: } \\
\text { Works without problems } \\
\text { Works without } \\
\text { Snowy conditions: no } \\
\text { problem regarding registra- } \\
\text { tion even in heavy snowfall }\end{array}$ \\
\hline $\begin{array}{l}\text { Reflection on } \\
\text { improve- } \\
\text { ment }\end{array}$ & $\begin{array}{l}\text { Specification of type of } \\
\text { injury related to severity } \\
\text { score }\end{array}$ & $\begin{array}{l}\text { Field for note writing/free } \\
\text { specification. } \\
\text { Further description of } \\
\text { transportation of injured } \\
\text { skier }\end{array}$ \\
\hline
\end{tabular}

troller 2 also report that the app works without problems in snowy conditions, and indicates that there is no problem during registration in heavy snow fall.

The reflection on improvements for ski patroller 1 includes indicating the specification of type of injury related to the corresponding severity score.

\section{B. Study 2: Heuristic Evaluation}

As far as the heuristic evaluation is concerned, we followed the methodology proposed by Jacob Nielsen and Robert L. Mack [29], by having each evaluator inspect the interface independently.

Nielsen on this work indicates that for performing a heuristic evaluation, three to five evaluators are sufficient.

In our case, four users are involved to examine and evaluate the interface and judge its compliance with recognized usability principles given in [29]. They have been instructed about how the interfaces work and for the purpose of the app, i.e., the evaluators were provided with hints on using the interface. In Table 3 we present Nielsen's ten heuristic checklist, provided to evaluators to help understanding the problems with the interface design, and how the system can be improved. As Nielsen has suggested, these ten heuristics should address most of the common usability problems.

The evaluators assessed the severity of each usability problem based on the scale $0-4$, as shown in Table 4 .

Overall, the results of the heuristic evaluation indicate very positive attitude and experience from the evaluators. The four evaluators see no usability problem at all for heuristic principle 2 and 6 , which correspond to the Match between system and real world, and Recognition rather than recall in Table III. 
TABLE III.

CASE STUDY RESULTS IN HEURISTIC EVALUATION

\begin{tabular}{|c|c|c|c|c|c|}
\hline & Nielsen's heuristics & \multicolumn{4}{|c|}{ Evaluators } \\
\hline \multirow[t]{2}{*}{1} & Visibility of system status & E1 & E2 & E3 & E4 \\
\hline & The app provides feedback about system status & 1 & 2 & 1 & 2 \\
\hline \multirow[t]{3}{*}{2} & Match between system and real world & & & & \\
\hline & Clear terminology, no jargon & 0 & 0 & 0 & 0 \\
\hline & Content is clear and follow conventions & 0 & 0 & 0 & 0 \\
\hline \multirow[t]{3}{*}{3} & User control and freedom & & & & \\
\hline & Logical structure of the app & 0 & 0 & 0 & 0 \\
\hline & Effective internal search & 1 & 1 & 1 & 1 \\
\hline \multirow[t]{4}{*}{4} & Consistency and standards & & & & \\
\hline & Links are clear and follow conventions & 0 & 0 & 0 & 2 \\
\hline & Various app functions are well integrated & 0 & 0 & 0 & 1 \\
\hline & Clear and consistent navigation throughout the app & 0 & 0 & 0 & 0 \\
\hline \multirow[t]{2}{*}{5} & Error prevention & & & & \\
\hline & Error messages problem & 1 & 1 & 0 & 1 \\
\hline \multirow[t]{3}{*}{6} & Recognition rather than recall & & & & \\
\hline & Objects, actions and options are visible & 0 & 0 & 0 & 0 \\
\hline & Organization of information makes sense & 0 & 0 & 0 & 0 \\
\hline \multirow[t]{5}{*}{7} & Flexibility and efficiency of use & & & & \\
\hline & Very easy to use and interact & 0 & 0 & 0 & 0 \\
\hline & Provides shortcuts for frequent tasks & 1 & 0 & 2 & 1 \\
\hline & Consistent way to return Home/Menu & 1 & 2 & 0 & 1 \\
\hline & Easy to identify current location & 1 & 2 & 2 & 0 \\
\hline \multirow[t]{5}{*}{8} & Aesthetic and minimalist design & & & & \\
\hline & Clean and simple design & 0 & 0 & 0 & 0 \\
\hline & Text and colors are consistent & 0 & 0 & 0 & 0 \\
\hline & Images are meaningful and serve a purpose & 0 & 0 & 2 & 0 \\
\hline & Simple navigation menu & 0 & 0 & 0 & 0 \\
\hline \multirow[t]{4}{*}{9} & Help users recognize, diagnose and recover from errors & & & & \\
\hline & (Error) Messages are explained in a plain language & 0 & 0 & 1 & 0 \\
\hline & Any problem is precisely indicated & 1 & 1 & 0 & 0 \\
\hline & A potential solution is constructively suggested & 2 & 2 & 2 & 2 \\
\hline 10 & Help and documentation & & & & \\
\hline & Help or Tips are available and clear & 2 & 2 & 1 & 2 \\
\hline
\end{tabular}

TABLE IV

RATING SCALE

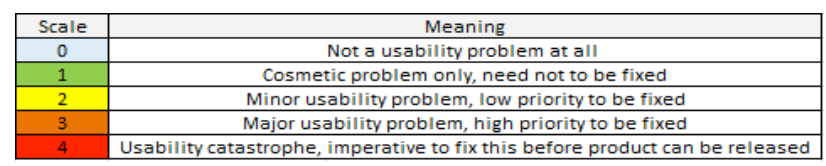

Regarding the Visibility of system status, evaluators think that there is a cosmetic or a minor usability problem with low priority to be fixed. Some other identified minor usability problems are related to Flexibility and efficiency of use, Help users recognize, diagnose and recover form errors, and Help and documentation. They face minor difficulties to:

i) identify current location,

ii) recognize a potential solution for a certain error, and

iii) find help or tips from the documentation.

None of the feedback from the evaluators relates to severity scaling 3 or 4 of the Nielsen's heuristic principles, meaning that there is no major usability problems or usability catastrophe involved with this prototype.

\section{CONCLUSIONS}

Our goal in this paper is to provide the architecture of the ski injury registration system developed in our lab, and give the implementation and evaluation approach for it. The main reason for developing such a system is to provide a correct, fast and secure communication among the parties of the "ski mountain, the local medical center and the hospital" chain. We have done two studies. In the first one, two ski patrollers in the Trysil Mountain tested our system using the traditional testing approach, and in the second one, four evaluators were engaged for heuristic evaluation of the system. Besides providing correct, fast and secure communication, the user friendliness of the developed apps is of importance. For that reason, we have employed a user centered design approach for the development of the ski patroller app interface.
Moreover, from the feedback we have received this is the future for handling the information regarding injured persons in alpine ski areas. The importance of a system that connects the different levels of treatment when somebody is injured is to be studied further. We foresee a system that links the different parts will have the ability to increase the capacity of the health system, enhance the overall knowledge of incidence and spectrum of injuries and thru that give a better opportunity to design prophylactic measures in order to reduce the incidence of injuries.

\section{ACKNOWLEDGMENT}

The authors gratefully acknowledge the grant from RFF-Norway (Regional Forskningsfond), Innlandet (\#235118). We also thank our team members, Klaus Karby, Sondre T. Johannessen, and Diana Marina Armijo Mendoza for all their contributions during the project in all phases.

\section{REFERENCES}

[1] Marco Bazzani, Davide Conzon, Andrea Scalera, Maurizio A. Spirito, Claudia Irene Trainito "Enabling the IoT paradigm in ehealth solutions through the VIRTUS middleware", the 11th IEEE International Conference on Trust, Security and Privacy in Computing and Communications, 2012 http://dx.doi.org/10.1109/trust com.2012.144

[2] Mari Carmen Domingo, "An overview of the Internet of Things for people with disabilities”, published in ,Journal of Network and Computer Applications", vol. 35, by Elsevier, 2012

[3] A. Prasad, J. Sorber, T. Stablein, D. Anthony, D. Kotz, Understanding sharing preferences and behavior for mHealth devices", Proceedings of the 2012 ACM workshop on Privacy in the electronic society, pp.117-128, Raleigh, USA.

[4] T. Wang, H. Jin, K. Nahrstedt, "mAuditor: mobile auditing framework for mHealth applications", Proceedings of the 2015 ACM Workshop on Pervasive Wireless Healthcare, pp. 7-12, Hangzhou, China. http://dx.doi.org/10.1145/2757290.2757291

[5] I. Demarin, L. Leko, M. Skrobo, H. Germano, P. Macedo, R.N Madeira, "The impact of stuttering: how can a mobile app help?", Proceedings of the 17th International 2015 ACM SIGACCESS Conference on Computers \& Accessibility, pp. 399-400, Lisbon, Portugal. http://dx.doi.org/10.1145/2700648.2811389

[6] F.F. Mueller, J. Marshall, R.A. Khot, S. Nylander, J. Tholander, "Understanding Sports-HCI by going Jogging at CHI", Proceedings of the 33rd Annual 2015 ACM Conference Extended Abstracts on Human Factors in Computing Systems, pp. 869-872, Seoul, Korea. http://dx.doi.org/10.1145/2702613.2727688

[7] L. Chittaro, "Mobile persuasion for health and safety promotion", Proceedings of the 17th 2015 International Conference on HumanComputer Interaction with Mobile Devices and Services Adjunct, pp. 878-882, Copenhagen, Denmark. http://dx.doi.org/10.1145/ 2786567.2786570

[8] S.Y. Yildirim, Y. Du, F. Dalipi, J.C. Jeppesen, "A novel system architecture for efficient management of skiing injuries", International IEEE Conference for Interactive Mobile Communication Technologies and Learning (IMCL), Thessaloniki, Greece, 2015. http://dx.doi.org/10.1109/IMCTL.2015.7359558

[9] RECCO ${ }^{\circledR}$, The RECCO ${ }^{\circledR}$ System [Internet]. 2013 [cited 10 Jan 2016] Available from: http://www.recco.com/the-recco-system

[10] International Ski Federation, FIS Medical Guide [Internet]. 2011 June [updated 2013, cited 10 Jan 2016 ] Available:http://www.fisski.com/mm/Document/documentlibrary/Medical/03/31/99/fismedical-guide-2013_Neutral.pdf

[11] A. Boukerche, Y. Ren, A Secure Mobile Healthcare System Using Trust-Based Multicast Scheme, IEEE JSAC, volume 27, pp.387399, 2009.

[12] K. Parane, N.C. Patil, S.R. Poojara, T.S. Kamble, Cloud based Intelligent Healthcare Monitoring System, 2014 IEEE International Conference on Issues and Challenges in Intelligent Computing 
Techniques, Ghaziabad, 2014. http://dx.doi.org/10.1109/icicict. 2014.6781365

[13] A. Banerjee, S.K.S. Gupta, Analysis of Smart Mobile Applications for Healthcare under Dynamic Context Changes, IEEE Transactions on Mobile Computing, 14(5), 2015. http://dx.doi.org/10.1109/TMC.2014.2334606

[14] G. Sebestyen, A. Hangan, S.Oniga, Z.Gal, eHealth Solutions in the Context of Internet of Things, 2014 IEEE International Conference on Automation, Quality and Testing, Robotics, Cluj-Napoca, Romania.

[15] F. Kart, L. E. Moser, P.M. Smith, Building a distributed ehealhcare system using SOA, IT Professional, 10(2), pp. 24-30, $2008 \mathrm{http}: / /$ dx.doi.org/10.1109/MITP.2008.22

[16] W.S. Ng, J.C.M. Teo, W.T. Ang, S. Viswanathan, C.K. Tham, Experiences on developing SOA based mobile healthcare services, IEEE Asia Pacific Services Computing Conference, Singapore 2009, pp. 498-501. http://dx.doi.org/10.1109/apscc.2009.5394079

[17] M. Savini, A. Ionas, A. Meier, C. Pop, H. Stomer, The eSana framework: Mobile services in eHealth using SOA, European Conference on Mobile Government, 2008.

[18] L. Griffin, C. Foley, E. de Leastar, A hybrid architectural style for complex healthcare scenarios, IEEE International Conference on Communications Workshops, pp. 1-6, Dresden, 2009. http://dx.doi.org/10.1109/iccw.2009.5208092

[19] L.W.F. Andry, D. Nicholson, A mobile application accessing patients health record through a REST API, the 4th International Conference on Health Informatics, pp. 27-32, 2011.

[20] E. Balka, S. Whitehouse, S.T. Coates, D. Andruisek, "Ski hill injuries and ghost charts: Socio-technical issues in achieving eHealth interoperability across jursidictions", Inf. Syst. Front 14 (2012), pp. 19-42. http://dx.doi.org/10.1007/s10796-011-9302-4

[21] A. Fedosov, M. Langheinrich, "From Start to Finish: Understanding group sharing behavior in a backcountry skiing community", Proceedings of the 17th ACM International Conference on $\mathrm{Hu}-$ man-Computer Interaction with Mobile Devices and Services Adjunct, pp. 758-765, Copenhagen, 2015,. http://dx.doi.org/10.1145/ 2786567.2793698

[22] B. Pfleging, A. Schmidt, F. Michahelles, Ubiqoitous Connectivity in the Mountains: Enhancing the Ski Experience, Pervasive Computing 12(2), IEEE CS, 2013, pp. 5-9, http://dx.doi.org/10.1109/MPRV.2013.38
[23] J.C. Jeppesen, Risk of injury in Norwegian alpine resorts - do we know it?, in the proceedings of PMU 2012.

[24] L. Richardson, S. Ruby, "RESTfil Web Services", O’Reilly 2007, ISBN:978-0-596-52926-0.

[25] F. Dalipi, D.M.A. Mendoza, A.S. Imran, S. Y. Yayilgan, "An Intelligent Model for Predicting the Occurrence of Skiing Injuries", $5^{\text {th }}$ IEEE National Symposium on Information Technology: Towards New Smart World, Riyadh, 2015.

[26] F. Dalipi, S.Y. Yayilgan, "Improving Prediction Accuracy of Skiing Injuries by Using Bayesian Regularization Neural Networks", $6^{\text {th }}$ IEEE International Conference on Computing, Communications, and Networking Technologies (ICCCNT2015), Dallas, 2015.

[27] J. Reekie, R. McAdam, A software architecture primer, Angophora Press, 2006

[28] T. Lowdermilk, User-Centered Design: A Developer's Guide to Building User-Friendly Applications, O’Reilly Media, 2013.

[29] J. Nielsen, R.L. Mack, "Usability Inspection Methods", John Wiley and Sons, New York, 1994. http://dx.doi.org/10.1145/ 259963.260531

\section{AUTHORS}

S. Yildirim-Yayilgan is an Associate Professor at Faculty of Computer Science and Media Technology, NTNU, Norway. (e-mail: sule.yildirim@ntnu.edu).

Y. Du was a master student at Faculty of Computer Science and Media Technology, Gjøvik University College. (e-mail: duduyang0404@gmail.com).

F. Dalipi is a Postdoctoral Fellow at Faculty of Computer Science and Media Technology, NTNU, Norway. (e-mail: fisnik.dalipi@ntnu.edu).

J.C. Jeppesen is with Scandinavian Ski Safety Institute, Norway. (e-mail: jcj@zyberia.no).

This work was supported in part by Regional Research Fund of Norway, Innlandet (\#235118).

Submitted, 31 January 2016. Published as resubmitted by the authors on 01 October 2016 